\title{
Reelin expression in human prostate cancer: a marker of tumor aggressiveness based on correlation with grade
}

Giuseppe Perrone ${ }^{1}$, Bruno Vincenzi ${ }^{2}$, Mariagiovanna Zagami ${ }^{1}$, Daniele Santini ${ }^{2}$, Roger Panteri ${ }^{3}$, Gerardo Flammia ${ }^{4}$, Alfio Verzí ${ }^{1}$, Daniela Lepanto ${ }^{1}$, Sergio Morini ${ }^{5}$, Antonio Russo ${ }^{6}$, Vivian Bazan ${ }^{6}$, Rosa M Tomasino ${ }^{7}$, Vincenza Morello ${ }^{7}$, Giuseppe Tonini ${ }^{2}$ and Carla Rabitti ${ }^{1}$

${ }^{1}$ Department of Surgical Pathology, Campus Bio-Medico University, Rome, Italy; ${ }^{2}$ Oncology Unit, Campus Bio-Medico University, Rome, Italy; ${ }^{3}$ Laboratory of Developmental Neuroscience, Campus Bio-Medico University, Rome, Italy; ${ }^{4}$ Department of Urologic Surgery, Campus Bio-Medico University, Rome, Italy; ${ }^{5}$ Department of Biomedical Research, Campus Bio-Medico University, Rome, Italy; ${ }^{6}$ Dipartimento di Discipline Chirurgiche ed Oncologiche, Sezione di Oncologia Medica, University of Palermo, Palermo, Italy and ${ }^{7}$ Department of Human Pathology, University of Palermo, Palermo, Italy

\begin{abstract}
Reelin is a glycoprotein that plays a critical role in the regulation of neuronal migration during brain development and, since reelin has a role in the control of cell migration, it might represents an important factor in cancer pathology. In this study, 66 surgical specimens of prostate cancer were analyzed for reelin expression by immunohistochemical method. The reelin expression was correlated with Gleason score and individual Gleason patterns. Reelin expression was found in $39 \%$ prostate cancers. Stromal tissues, normal epithelial cells and prostate intraepithelial neoplasia (PIN) of any grade around and distant from cancer were always negative for reelin. Reelin was found in malignant prostatic epithelial glands of $50 \%$ cases Gleason score $10,52 \%$ Gleason score $9,56 \%$ Gleason score $8,18 \%$ Gleason score 7 , while no sample of prostate cancers with Gleason score 6 showed reelin expression $(P=0,005)$. As reelin staining is frequently found in high Gleason score prostate cancers, we explored whether reelin expression is influenced by single Gleason patterns. While Gleason 3 pattern did not show reelin immunoreactivity, reelin expression was found in $35 \%$ Gleason 4 patterns and $45 \%$ Gleason 5 patterns $(P<0.001)$. Our results demonstrated for the first time that reelin is expressed in prostate cancer and not in benign prostate tissue and its expression occurs in higher Gleason score and correlates significantly with increasing of single Gleason patterns. This suggests reelin may behave as a specific histological marker and may represent a useful biomarker to predict aggressive phenotypic behavior of prostatic cancer cells.
\end{abstract}

Modern Pathology (2007) 20, 344-351. doi:10.1038/modpathol.3800743; published online 2 February 2007

Keywords: reelin; prostate; cancer; Gleason score; immunohistochemistry

Reelin is a $420 \mathrm{kDa}$ secreted extracellular glycoprotein that plays a critical role in the regulation of neuronal migration during brain development. ${ }^{1}$ Reelin is thought to guide migrating neurons by interacting with two cell surface receptors, very low density lipoprotein receptor (VLDLR) and apolipoprotein E receptor 2 (ApoER2), and by activating a tyrosine kinase signalling cascade that instructs

Correspondence: Dr G Perrone, MD, Department of Surgical Pathology, Campus Bio Medico University, Via Emilio Longoni 47, 00155 Rome, Italy.

E-mail: g.perrone@unicampus.it

Received 2 October 2006; revised 20 November 2006; accepted 27 November 2006; published online 2 February 2007 neurons to reach their correct laminar position in the cortex; ${ }^{2}$ reelin modulates the cytoskeletal organization and behavior of migrating neurons by regulating the phosphorylation state of the microtubule-stabilizing protein tau; mice that are mutant for reelin show high levels of tau phosphorylation suggesting that defective reelin signalling leads to tau hyperphosphorylation. ${ }^{3}$ Although most studies have focused on the role of reelin in central neural system (CNS) development, recent data have shown that reelin is also expressed in adult peripheral tissues, including the peripheral neural system, ${ }^{4}$ liver, kidney, testis, ovary, ${ }^{5}$ odontoblasts, ${ }^{6}$ plasma cells, ${ }^{7}$ serum, ${ }^{8}$ acinar and ductal pancreatic epithelial cells, Langherhans islet cells and autonomic 
peripheral nerves, ${ }^{9}$ thereby proposing a wide spectrum of biological functions.

Although reelin dysfunction has been implicated in the pathogenesis of brain malformation and several psychiatric disorders, ${ }^{10}$ its biological role in the development and function of other organs remains obscure. As reelin has a role in the control of cell migration, it might represents an important factor in cancer invasion and metastasis.

Wetmore et $a l^{11}$ demonstrated for the first time reelin expression in cancer pathology reporting the presence of reelin mRNA in mice medulloblastoma tissue.

Reelin expression in non-cerebral tumor pathology has also been reported by immunohistochemical methods in esophageal ${ }^{12}$ and pancreatic ${ }^{9}$ cancer.

In order to further understand the role of reelin in neoplastic pathology, we initially investigated reelin expression by immunohistochemistry in a large series of most frequent human cancers (skin, colorectal, gastric, neuroendocrine, breast, prostate). In this initial study, reelin expression was found only in two prostate cancers. This finding led us to further investigate reelin expression in a larger series of prostate cancers.

\section{Materials and methods}

\section{Case Selection}

Reelin expression was evaluated in ten skin, colorectal, gastric, breast, neuroendocrine tumors and prostate cancer resection specimens (total of 60 cases), retrieved from the files of the Surgical Pathology Unit of the University Campus BioMedico. Tissue samples were fixed in $4 \%$ neutral buffered formaldehyde and embedded in paraffin. Routine hematoxylin- and eosin-staining was performed on the sections for histopathologic evaluation. Tumor histology and grade were evaluated at primary diagnosis and extracted from the pathology reports. They were re-evaluated according to the International Union Against Cancer. ${ }^{13}$ Consecutive $3 \mu \mathrm{m}$ sections were cut from samples used for routine diagnostic purposes. Reelin expression was evaluated by immunohistochemical methods.

According to the initial immunohistochemical results, another 56 prostate cancer cases were further selected from the files of the Surgical Pathology Unit of the University Campus BioMedico and the Institute of Pathology of the University of Palermo. No patient had received chemotherapy, hormonotherapy or radiation therapy before surgery.

One of the pathologists (MZ) re-examined the hematoxylin- and eosin-stained slides, classified the tumors according to commonly used criteria ${ }^{13}$ and representative blocks were chosen for reelin immunohistochemical evaluation. Within the 66 prostate cancer cases studied, 31 were radical prostatectomies, 19 enucleations and 16 TURPs. The Gleason score findings are reported in Table 2. High-grade prostatic intraepithelial neoplasia (PIN), the direct precursor of prostate cancer, was present in 31 of the 66 prostate cancers included in this study. For reelin immunohistochemical evaluation, $3 \mu \mathrm{m}$ sections were cut from the paraffin blocks corresponding to the slides selected.

\section{Antibodies and Reagents}

Unless otherwise stated, all reagents were from DakoCytomation Inc. (Carpinteria, CA, USA). In the present study, two primary antibodies against reelin protein were used: the mouse monoclonal antibody (Calbiochem: 142 clone; 1/500) that recognizes an epitope localized in the $\mathrm{N}$-terminal region of reelin ${ }^{14}$ and, to confirm the specificity of reelin staining, 10 randomly select cases of prostate cancer were immunostained with the rabbit polyclonal antibody (Santa Cruz: H-221 clone; 1/200) that recognizes an epitope localized in the C-terminal region of reelin. ${ }^{15}$

\section{Immunohistochemical Staining}

Immunohistochemical staining was performed by the streptavidin-biotin method. In brief, sections were deparaffinized and endogenous peroxidase activity was blocked by incubating the sections in $3 \%$ hydrogen peroxide. The slides were washed with TBS, treated with horse serum for $30 \mathrm{~min}$ at room temperature to block non-specific binding, incubated with the anti-reelin mouse monoclonal (142 clone) and rabbit polyclonal (H-221 clone) antibodies for $2 \mathrm{~h}$ at room temperature. After washing three times with TBS ( 5 min each wash), sections were incubated with a biotinylated anti-mouse/antirabbit (LSAB2) antibody for $10 \mathrm{~min}$. They were then washed three times with in TBS, treated with streptavidin-biotin-peroxidase complex for $10 \mathrm{~min}$ and then washed again with TBS for three times. Finally, specimens were incubated with $3,3^{\prime}$-diaminobenzidine (DAB) for $3 \mathrm{~min}$, followed by hematoxylin counterstaining. All the sections were examined by light microscopy by two investigators (GP and DL) blind to the corresponding clinicopathological data to assess the presence or absence of reelin immunostaining and its distribution. Neural structures (fibres and ganglion) present in the tissue sections were used as positive internal control. $^{9}$ As negative control some slides were processed without primary antibody and were included in each staining run.

Reelin immunostaining was evaluated in terms of the percentage of reelin immunoreactive cells over a total of at least 1000 tumor cells. Only prostate cancers with a percentage of immunostained cells $\geq 10 \%$ were considered as positive. 
We evaluated reelin expression by assessing immunostaining in the various Gleason patterns in addition to Gleason score.

\section{Statistic Methods}

Reelin expression between different Gleason score and different Gleason patterns were compared using logistic regression analysis. Spearman's rank correlation test was used to assess relationships between ordinal data. $P<0.05$ were regarded as statistically significant in tailed tests. SPSS software (version 13.00, SPSS, Chicago) was used for statistical analysis.

\section{Results}

\section{Reelin Expression in Different Cancer Types}

Among the different cancers studied in the initial analysis, only two prostate cancers resulted positive for reelin. Table 1 summarizes the principal pathological characteristics of these neoplastic lesions. Stromal tissue, vascular structures, normal epithelial cells did not show reelin expression. On the contrary, neural structures were positively stained for reelin. In particular, ganglia showed cytoplasmic staining for reelin.

On the basis of these preliminary results, reelin expression was further evaluated in a larger series of prostate cancers.

\section{Reelin Expression in Prostate Cancer}

Another 56 prostate cancers were selected on the basis of the corresponding Gleason score and were processed by immunohistochemistry for reelin expression.

Stromal tissues and normal glandular epithelial cells around and distant from the cancer were always negative for reelin. All prostate intraepithelial neoplasia (PIN) lesions of any grades were also negative. The neural structures present in the sections examined were positively stained for reelin, thus were used as internal positive control (Figure 1).

Of a total of 66 cases, 26 (39\%) prostate cancers showed reelin expression. Table 2 reports the Gleason score and the immunohistochemical findings obtained with anti-reelin clone 142 antibody of all prostate cancers studied. Reelin expression was evenly distributed throughout the cancer in those cases with heterogeneous staining. Any difference in staining relating to the different types of tissue examined was found (data not shown). Furthermore, no difference in terms of reelin expression was found among cytoarchitectural patterns.

Similar immunohistochemical results were obtained with the two different antibodies (142 clone and H-221 clone) showing a clear cytoplasmic positivity for reelin in malignant neoplastic cells (data not shown).

\section{Relationship between Reelin Expression and Gleason Score}

Of 66 prostate cancers, 10 (15\%) specimens were categorized as Gleason score 6, $11(17 \%)$ as Gleason score 7, $18(27 \%)$ as Gleason score 8, 23 $(35 \%)$ as Gleason score 9 and $4(6 \%)$ as Gleason score 10.

Table 1 Preliminary study on reelin expression in cancer pathology

\begin{tabular}{|c|c|c|c|c|c|c|}
\hline Cancer lesions & No. & Histotype & No. & Grade & No. & No. of reelin positive tumors \\
\hline \multirow[t]{3}{*}{ Skin } & \multirow[t]{3}{*}{10} & Basal cell & 5 & & 5 & 0 \\
\hline & & Squamous cell & 5 & Low & 3 & 0 \\
\hline & & & & High & 2 & 0 \\
\hline \multirow[t]{2}{*}{ Colorectal } & \multirow[t]{2}{*}{10} & \multirow[t]{2}{*}{ Adenocarcinoma } & \multirow[t]{2}{*}{10} & Moderate & 5 & 0 \\
\hline & & & & High & 5 & 0 \\
\hline \multirow[t]{3}{*}{ Gastric } & \multirow[t]{3}{*}{10} & Intestinal type & 5 & Low & 3 & 0 \\
\hline & & & & High & 2 & 0 \\
\hline & & Diffuse type & 5 & High & 5 & 0 \\
\hline \multirow[t]{3}{*}{ Breast } & \multirow[t]{3}{*}{10} & Ductal & 5 & Low & 3 & 0 \\
\hline & & & & High & 2 & 0 \\
\hline & & Lobular & 5 & High & 5 & 0 \\
\hline \multirow[t]{3}{*}{ Neuroendocrine } & \multirow[t]{3}{*}{10} & Gastric & 4 & & 4 & 0 \\
\hline & & Duodenum & 2 & & 2 & 0 \\
\hline & & Appendix & 4 & & 4 & 0 \\
\hline \multirow[t]{5}{*}{ Prostate } & \multirow[t]{5}{*}{10} & \multirow[t]{5}{*}{ Adenocarcinoma } & \multirow[t]{5}{*}{10} & Gleason 6 & 2 & 0 \\
\hline & & & & Gleason 7 & 2 & 0 \\
\hline & & & & Gleason 8 & 2 & 0 \\
\hline & & & & Gleason 9 & 2 & 1 \\
\hline & & & & Gleason 10 & 2 & 1 \\
\hline
\end{tabular}



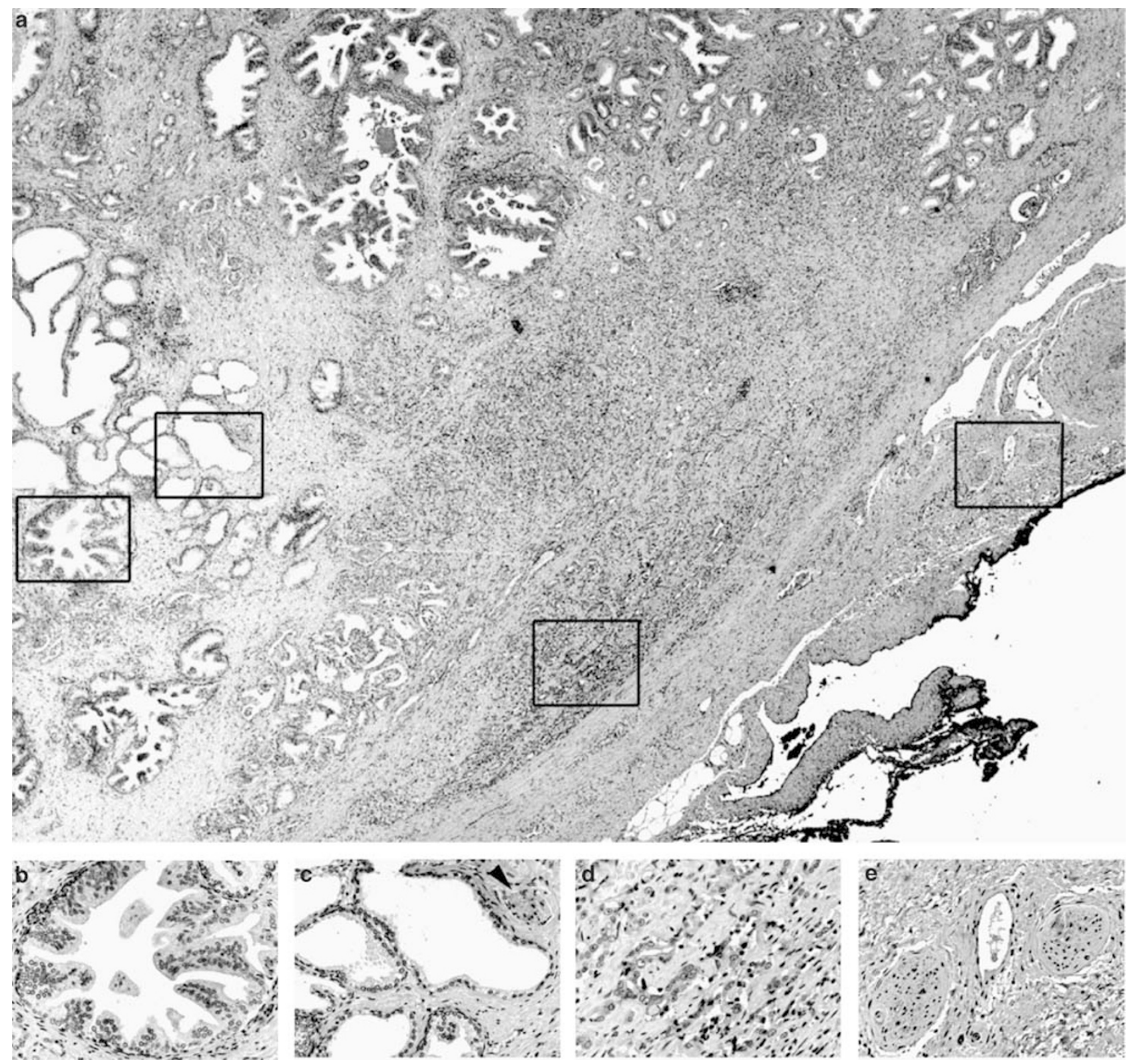

Figure 1 (a) Immunohistochemical analysis of reelin expression (Mab 142) in a prostate specimen with a Gleason 8(4+4) cancer. (b-e) Details of (a). (b) PIN lesions, (c) nonneoplastic prostate epithelial cells and stromal tissue resulted negative for reelin staining in contrast to positive labelling in a peripheral nerve tissue (arrow). Immunolabelling for reelin is identified diffusely in prostate cancer. (d) Clearly shows the cytoplasmic staining pattern of reelin in prostate cancer at higher magnification. (e) The neural structures present in the section were positively stained for reelin, thus were used as internal positive control. Original magnification: (a) $\times 20$; (b-e) $\times 200$.

Reelin expression was found in malignant prostatic epithelial glands of $2 / 4(50 \%)$ cases Gleason score 10, 12/23 (52\%) Gleason score 9, 10/18 (56\%) Gleason score 8, 2/11 (18\%) Gleason score 7, while no sample of prostate cancers with Gleason score 6 showed reelin expression.

With the logistic regression analysis, a significant statistical difference was detected among Gleason scores as it concerns reelin expression $(P=0.005)$, suggesting that reelin expression is modified by differentiation grade (Table 3 ).
The Gleason score is the sum of the two most frequently occurring Gleason patterns within the same prostate specimen. ${ }^{16}$

As reelin staining is frequently found in high Gleason score prostate cancers, we explored whether reelin expression is influenced by single Gleason patterns.

As expected, while Gleason 3 pattern did not show reelin immunoreactivity, reelin expression was found in 17/48 (35\%) Gleason 4 patterns and 14/31 (45\%) Gleason 5 patterns (Figure 2). Also the 
Table 2 Gleason grade and Gleason patterns of all prostate cancers studied and immunohistochemical findings obtained with anti-reelin clone 142 antibody

\begin{tabular}{|c|c|c|c|c|c|c|}
\hline No. & Age & $\begin{array}{l}\text { Primary } \\
\text { Gleason } \\
\text { pattern }\end{array}$ & $\begin{array}{l}\% \text { of } \\
\text { reelin } \\
\text { positive } \\
\text { cells on } \\
\text { primary } \\
\text { Gleason }\end{array}$ & $\begin{array}{c}\text { Secondary } \\
\text { Gleason } \\
\text { pattern }\end{array}$ & $\begin{array}{l}\% \text { of } \\
\text { reelin } \\
\text { positive } \\
\text { cells on } \\
\text { secondary } \\
\text { Gleason }\end{array}$ & $\begin{array}{c}\text { Gleason } \\
\text { score }\end{array}$ \\
\hline 1 & 71 & 5 & 43 & - & - & 10 \\
\hline 2 & 58 & 5 & 71 & - & - & 10 \\
\hline 3 & 75 & 5 & 0 & - & - & 10 \\
\hline 4 & 68 & 5 & 0 & - & - & 10 \\
\hline 5 & 85 & 5 & 59 & 4 & 51 & 9 \\
\hline 6 & 81 & 5 & 21 & 4 & 0 & 9 \\
\hline 7 & 59 & 5 & 46 & 4 & 0 & 9 \\
\hline 8 & 74 & 5 & 0 & 4 & 0 & 9 \\
\hline 9 & 62 & 5 & 0 & 4 & 0 & 9 \\
\hline 10 & 56 & 5 & 5 & 4 & 0 & 9 \\
\hline 11 & 66 & 5 & 85 & 4 & 0 & 9 \\
\hline 12 & 77 & 5 & 89 & 4 & 10 & 9 \\
\hline 13 & 61 & 5 & 72 & 4 & 0 & 9 \\
\hline 14 & 66 & 5 & 0 & 4 & 0 & 9 \\
\hline 15 & 73 & 4 & 0 & 5 & 0 & 9 \\
\hline 16 & 76 & 4 & 0 & 5 & 77 & 9 \\
\hline 17 & 65 & 4 & 0 & 5 & 0 & 9 \\
\hline 18 & 71 & 4 & 0 & 5 & 0 & 9 \\
\hline 19 & 65 & 4 & 0 & 5 & 0 & 9 \\
\hline 20 & 73 & 4 & 0 & 5 & 75 & 9 \\
\hline 21 & 78 & 4 & 0 & 5 & 0 & 9 \\
\hline 22 & 54 & 4 & 71 & 5 & 73 & 9 \\
\hline 23 & 74 & 4 & 0 & 5 & 0 & 9 \\
\hline 24 & 78 & 4 & 41 & 5 & 0 & 9 \\
\hline 25 & 65 & 4 & 0 & 5 & 0 & 9 \\
\hline 26 & 81 & 4 & 52 & 5 & 55 & 9 \\
\hline 27 & 70 & 4 & 37 & 5 & 29 & 9 \\
\hline 28 & 70 & 5 & 0 & 3 & 0 & 8 \\
\hline 29 & 75 & 5 & 0 & 3 & 0 & 8 \\
\hline 30 & 73 & 5 & 49 & 3 & 0 & 8 \\
\hline 31 & 74 & 3 & 0 & 5 & 0 & 8 \\
\hline 32 & 62 & 4 & 0 & - & - & 8 \\
\hline 33 & 66 & 4 & 58 & - & - & 8 \\
\hline 34 & 76 & 4 & 0 & - & - & 8 \\
\hline 35 & 77 & 4 & 92 & - & - & 8 \\
\hline 36 & 80 & 4 & 89 & - & - & 8 \\
\hline 37 & 68 & 4 & 0 & - & - & 8 \\
\hline 38 & 72 & 4 & 49 & - & - & 8 \\
\hline 39 & 64 & 4 & 53 & - & - & 8 \\
\hline 40 & 68 & 4 & 0 & - & - & 8 \\
\hline 41 & 80 & 4 & 20 & - & - & 8 \\
\hline 42 & 80 & 4 & 43 & - & - & 8 \\
\hline 43 & 77 & 4 & 62 & - & - & 8 \\
\hline 44 & 75 & 4 & 0 & - & - & 8 \\
\hline 45 & 59 & 4 & 34 & - & - & 8 \\
\hline 46 & 63 & 4 & 57 & 3 & 0 & 7 \\
\hline 47 & 70 & 4 & 0 & 3 & 0 & 7 \\
\hline 48 & 54 & 4 & 0 & 3 & 0 & 7 \\
\hline 49 & 64 & 4 & 0 & 3 & 0 & 7 \\
\hline 50 & 68 & 4 & 0 & 3 & 0 & 7 \\
\hline 51 & 81 & 4 & 5 & 3 & 0 & 7 \\
\hline 52 & 62 & 3 & 0 & 4 & 3 & 7 \\
\hline 53 & 67 & 3 & 0 & 4 & 0 & 7 \\
\hline 54 & 66 & 3 & 0 & 4 & 0 & 7 \\
\hline 55 & 68 & 3 & 0 & 4 & 0 & 7 \\
\hline 56 & 68 & 3 & 0 & 4 & 54 & 7 \\
\hline 57 & 57 & 3 & 0 & - & - & 6 \\
\hline 58 & 75 & 3 & 0 & - & - & 6 \\
\hline 59 & 64 & 3 & 0 & - & - & 6 \\
\hline 60 & 75 & 3 & 0 & - & - & 6 \\
\hline 61 & 66 & 3 & 0 & - & - & 6 \\
\hline 62 & 68 & 3 & 0 & - & - & 6 \\
\hline 63 & 68 & 3 & 0 & - & - & 6 \\
\hline
\end{tabular}

Table 2 Continued

\begin{tabular}{ccccccc}
\hline No. Age Primary & $\begin{array}{c}\text { \% of } \\
\text { reelin } \\
\text { pleasitive } \\
\text { pattern } \\
\text { cells on } \\
\text { primary } \\
\text { Gleason }\end{array}$ & $\begin{array}{c}\text { Secondary } \\
\text { Gleason } \\
\text { pattern }\end{array}$ & $\begin{array}{c}\text { \% of } \\
\text { reelin } \\
\text { positive } \\
\text { cells on } \\
\text { secondary } \\
\text { Gleason }\end{array}$ & $\begin{array}{c}\text { Gleason } \\
\text { score }\end{array}$ \\
\hline 64 & 71 & 3 & 0 & - & - & 6 \\
65 & 61 & 3 & 0 & - & - & 6 \\
66 & 72 & 3 & 0 & - & - & 6 \\
\hline
\end{tabular}

Table 3 Regression analysis between Gleason score and reelin expression

\begin{tabular}{lcr}
\hline & Reelin expression (\%) & Total \\
\hline Gleason grade & & \\
6 & $0(0)$ & 10 \\
7 & $2(18)$ & 11 \\
8 & $10(56)$ & 18 \\
9 & $12(52)$ & 23 \\
10 & $2(50)$ & 4 \\
Total & $26(40)$ & 66 \\
\hline
\end{tabular}

Logistic regression: odds ratio $=2.136 ; P=0.005$

difference in terms of reelin expression within different Gleason patterns resulted statistical significant $(P<0,001)$ (Table 4). Furthermore, in this context, a highly positive statistical correlation was found between the percentage of reelin positive cells and the Gleason pattern (rho: 0.372; $P<0.0001$ ). This finding suggests that reelin expression in higher Gleason scores is a result of the increased expression of reelin associated with an increased Gleason pattern.

\section{Discussion}

Reelin is a large protein of the extracellular matrix that plays an important role in the lamination of several brain structures during the cortical development. ${ }^{17,18}$ Recently, it was demonstrated that reelin is also expressed in organs and compartments outside of the $\mathrm{CNS}^{4-7,9}$ where it might regulate cellular differentiation and cellular migration. As these processes participate in neoplastic transformation and progression, we investigated reelin expression in a large series of neoplastic lesions and report for the first time reelin expression in prostate cancers.

In our study, we observed $39 \%$ prostate cancers showing reelin expression. Stromal tissues and normal glandular epithelial cells around and distant from cancer were always negative for reelin. PIN lesions of any grade were also reelin negative. The neural structures present within the tissue examined sections showed a positive immunoreactivity 

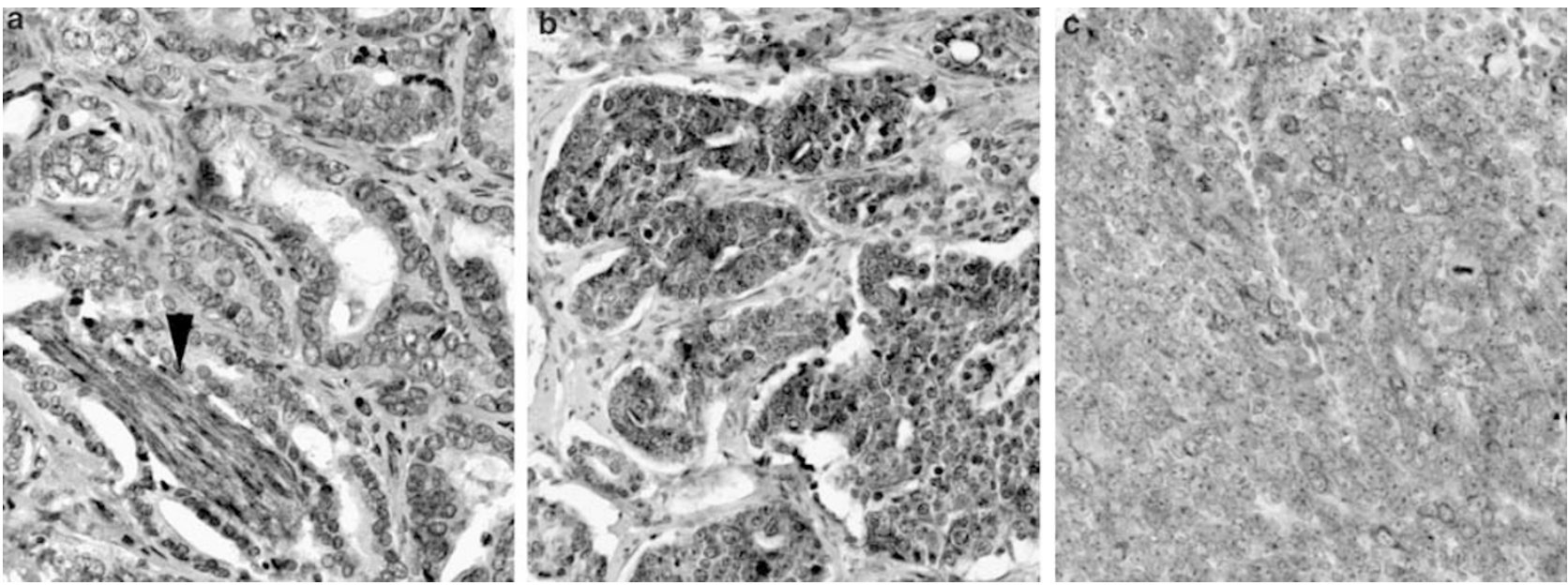

Figure 2 Immunohistochemical analysis of reelin in prostate cancer. (a) Gleason 3 pattern did not show reelin immunoreactivity. The neural structures present in the section were positively stained (arrow), which serve as an internal control. Reelin immunoreactivity was found in 35\% Gleason 4 (b) and in 45\% Gleason 5 pattern (c). Original magnification: $(\mathbf{a}-\mathbf{c}) \times 200$.

Table 4 Regression analysis between differ ent Gleason patterns and reelin expression

\begin{tabular}{lcr}
\hline & Reelin expression (\%) & Total \\
\hline Gleason pattern & $0(0)$ & \\
3 & $17(35)$ & 25 \\
4 & $14(45)$ & 48 \\
5 & $31(30)$ & 104 \\
Total & & \\
\hline
\end{tabular}

Logistic regression: odds ratio $=3.266 ; P=0.001$.

for reelin, thus were used as an internal positive control. ${ }^{9}$ According to our results reelin is expressed specifically in cancer lesions while it does not show up in normal and hypertrophic tissue. Reelin is not also expressed in PIN lesions, thus suggesting it behaves as a specific histological marker for prostate cancer.

Our results are consistent with another recent report about reelin expression in cancer pathology. Wang et $a l^{12}$ found reelin expression in esophageal cancer through RT-PCR and immunohistochemical analysis on normal and tumor esophageal tissue. Low expression of reelin was detected in all normal esophageal tissues, while increased expression and strong immunoreactivity for reelin was detected in $87.5 \%$ of esophageal carcinoma tissues studied.

Furthermore, Sato et $a l^{9}$ have recently demonstrated the expression of reelin protein in primary pancreatic cancers by immunohistochemical experiments performed using tissue microarrays on a large series of primary pancreatic adenocarcinomas and corresponding nonneoplastic pancreatic tissues. Of 294 primary pancreatic cancers, 28\% showed diffuse immunolabeling for reelin. In nonneoplastic pancreas, immunolabeling for reelin was identified in the cytoplasm of various cell types, including normal ductal epithelial cells, acinar cells, islet cells, and autonomic peripheral nerves. Moreover they demonstrated that reelin is a frequent target for epigenetic silencing in pancreatic neoplasms, and loss of reelin function can confer a more aggressive phenotype to pancreatic cancer cells, thus showing an association between reelin expression and the progression of cancer.

In the present study, we show that an increase of reelin expression is more frequently associated with higher Gleason scores of prostate cancers. The results of our study, in agreement with the other reports, are consistent with the hypothesis that reelin may play a key role in cancer pathology.

Moreover, prostate cancer is the leading cause of death due to malignancy, accounting for $40 \%$ of all cancers diagnosed in men, and the frequency of all forms of the disease increases with age. ${ }^{19}$ The early detection of molecular changes which are predictive of invasiveness and metastatic behavior is essential to clinical decision-making. Interestingly, in our study, a positive statistical correlation was found between reelin expression and Gleason score.

Gleason grading is the most widely used pathological grading system in patients with prostate cancer. ${ }^{16}$ Although Gleason grading is commonly used as a predictor of disease progression, it is limited by lack of total accuracy in distinguishing patients at risk of disease progression from patients with stable disease. The 20-year prostate cancer mortality rate for patients with Gleason 5, 6, 7 and $8-10$ is $14,27,45$ and $66 \%$ respectively, suggesting that each Gleason score consists of an heterogeneous population of patients with both progressive and stable forms of disease. ${ }^{20}$ Therefore, there is a clear need to identify novel biomarkers that can further improve or predict clinical progression in addition 
to the Gleason scoring system. Our predictive capability of prostate cancer incidence, recurrence following treatment and disease progression has improved since the introduction of validated nomograms, which use multiple continuous variables for prediction. ${ }^{21}$ In addition to clinical parameters such as tumor grade and stage, serum PSA and other serum and tissue molecular markers, such as interleukin receptor 6 and transforming growth factor $\beta 1$, are now being included in experimental nomograms to improve the predictive accuracy. ${ }^{22}$ Since the present study demonstrates that reelin expression correlates significantly with increasing Gleason score, it is conceivable that reelin may represent a useful biomarker to predict aggressive phenotypic behavior of prostatic cancer cells and thus may be potentially incorporated in future nomograms.

Besides demonstrating reelin expression in highgrade prostate cancers, we have also shown that reelin occurs more frequently in $\geq$ Gleason 4 pattern compared to Gleason 3 pattern prostate cancer. There is a debate in the urologic community with regard to the clinical significance of individual Gleason patterns within the total Gleason scoring system. ${ }^{23}$ For example, patients with a Gleason score 7 which show a Gleason score $4+3$ tend to have higher biochemical recurrence rate than patients with a Gleason score $3+4$, suggesting that an individual Gleason pattern can also represent an independent predictor of disease progression. ${ }^{24}$ Our study confirms that reelin expression occurs at significantly higher rate in Gleason patterns 4 or 5 compared to Gleason patterns 3, which suggests that reelin could be a novel biomarker for high Gleason patterns. The finding that reelin expression differs significantly between Gleason patterns 3 and 4 suggests an association of reelin with a more aggressive malignant phenotype. Characteristic gene expression patterns characteristically associated with specific Gleason scores have already been shown for prostate cancers. ${ }^{25}$

As reelin is involved in the control of cell migration and the latter represents an important factor in cancer invasion and metastasis, further research on the role of reelin in prostate cancer may be helpful to understand the molecular mechanisms of prostate cancer aggressiveness and may provide a new target for diagnosis, prognosis and therapy of prostate carcinoma.

\section{References}

1 Frotscher M. Cajal-Retzius cells, Reelin, and the formation of layers. Curr Opin Neurobiol 1998;8: $570-575$.

2 Tissir F, Goffinet AM. Reelin and brain development. Nat Rev Neurosci 2003;4:496-505.

3 Hiesberger T, Trommsdorff M, Howell BW, et al. Direct binding of Reelin to VLDL receptor and ApoE receptor 2 induces tyrosine phosphorylation of disabled-1 and modulates tau phosphorylation. Neuron 1999;24:481-489.

4 Panteri R, Mey J, Zhelyaznik N, et al. Reelin is transiently expressed in the peripheral nerve during development and is upregulated following nerve crush. Mol Cell Neurosci 2006;32:133-142.

5 Ikeda Y, Terashima T. Expression of reelin, the gene responsible for the reeler mutation, in embryonic development and adulthood in the mouse. Dev Dyn 1997;210:157-172.

6 Maurin JC, Couble ML, Didier-Bazes M, et al. Expression and localization of reelin in human odontoblasts. Matrix Biol 2004;23:277-285.

7 Underhill GH, George D, Bremer EG, et al. Gene expression profiling reveals a highly specialized genetic program of plasma cells. Blood 2003;101: 4013-4021.

8 Smalheiser NR, Costa E, Guidotti A, et al. Expression of reelin in adult mammalian blood, liver, pituitary pars intermedia, and adrenal chromaffin cells. Proc Natl Acad Sci USA 2000;97:1281-1286.

9 Sato N, Fukushima N, Chang R, et al. Differential and epigenetic gene expression profiling identifies frequent disruption of the RELN pathway in pancreatic cancers. Gastroenterology 2006;130:548-565.

10 Fatemi SH. Reelin glycoprotein: structure, biology and roles in health and disease. Mol Psychiatry 2005;10: 251-257.

11 Wetmore C, Eberhart DE, Curran T. The normal patched allele is expressed in medulloblastomas from mice with heterozygous germ-line mutation of patched. Cancer Res 2000;60:2239-2246.

12 Wang Q, Lu J, Yang C, et al. CASK and its target gene Reelin were co-upregulated in human esophageal carcinoma. Cancer Lett 2002;179:71-77.

13 Sobin LH, Wittekind C (eds). TNM Classification of Malignant Tumours, 6th edn. UICC International Union Against Cancer. Wiley-Liss: New York, 2002.

14 de Bergeyck V, Naerhuyzen B, Goffinet AM, et al. A panel of monoclonal antibodies against reelin, the extracellular matrix protein defective in reeler mutant mice. J Neurosci Methods 1998;82:17-24.

15 Krathwohl MD, Kaiser JL. Chemokines promote quiescence and survival of human neural progenitor cells. Stem Cells 2004;22:109-118.

16 Gleason DF. Histologic grading and clinical staging of prostatic carcinoma. In: Tannenbaum M (ed). Urologic pathology: The Prostate. Lea and Febiger: Philadelphia, 1977.

17 D’Arcangelo G, Miao GG, Chen S-C, et al. A protein related to extracellular matrix proteins deleted in the mouse mutant reeler. Nature 1995;374:719-723.

18 Hirotsune S, Takahara T, Sasaki N, et al. The reeler gene encodes a protein with an EGF-like motif expressed by pioneer neurons. Nat Genet 1995;10: 77-83.

19 La Vecchia C, Negri E, Levi F, et al. Cancer mortality in Europe: effects of age, cohort of birth and period of death. Eur J Cancer 1998;34:118-141.

20 Albertsen PC, Hanley JA, Fine J. 20-year outcomes following conservative management of clinically localized prostate cancer. JAMA 2005;293:2095-2101.

21 Kattan MW, Scardino PT. Prediction of progression: Nomograms of clinical utility. Clin Prostate Cancer 2002;1:90-96.

22 Kattan MW, Shariat SF, Andrews B, et al. The addition of interleukin-6 soluble receptor and transforming 
growth factor beta1 improves a preoperative nomogram for predicting biochemical progression in patients with clinically localized prostate cancer. J Clin Oncol 2003;21:3573-3579.

23 Merrick GS, Butler WM, Galbreath RW, et al. Biochemical outcome for hormone-naive patients with Gleason score $3+4$ versus $4+3$ prostate cancer undergoing permanent prostate brachytherapy. Urology 2002;60:98-103.
24 Herman CM, Kattan MW, Ohori M, et al. Primary Gleason pattern as a predictor of disease progression in gleason score 7 prostate cancer: a multivariate analysis of 823 men treated with radical prostatectomy. Am J Surg Pathol 2001;25:657-660.

25 Stamey TA, Caldwell MC, Fan Z, et al. Genetic profiling of Gleason grade 4/5 prostate cancer: which is the best prostatic control tissue? J Urol 2003;170: 2263-2268. 